Annales Geophysicae, 23, 3111-3113, 2005

SRef-ID: 1432-0576/ag/2005-23-3111

(C) European Geosciences Union 2005

\title{
Space weather effects on the MAGION-4 and MAGION-5 solar cells
}

\author{
P. Tř́ska, A. Czapek, J. Chum, F. Hruška, J. Šimůnek, J. Šmilauer, V. Truhlík, and J. Vojta \\ Institute of Atmospheric Physics, Acad. Sci. Czech Republic, Boení II, 14131 Prague 4, Czech Republic \\ Received: 17 February 2005 - Revised: 2 June 2005 - Accepted: 6 June 2005 - Published: 22 November 2005 \\ Part of Special Issue "1st European Space Weather Week (ESWW)"
}

\begin{abstract}
Data on solar array efficiency measured on board two Czech MAGION micro-satellites between August 1995 and June 2002, during the period of increasing and high solar activity, were used to study the space weather effects on photo-voltaic solar cells. A stronger degradation of the solar array was observed on MAGION-5 in comparison with MAGION-4. This fact can be explained by the essential difference between the two orbits. The MAGION-5 s/c was in the radiation belts more than $40 \%$ of the time, whereas the MAGION-4 was only present about $4 \%$ of the time. The experimental data refer to periods of low as well as high solar activity, with an enhanced occurrence of strong solar events. The evaluation of the data set covering a period of more than 6 years has shown that solar proton flares can have an almost immediate effect on the solar array efficiency. However, in the case of MAGION-5, an important role in solar cell degradation is played by the long-term effect of energetic particles in the radiation belts. Periods with a distinctly steeper decrease in the solar array output power were observed and can be explained by an increase of particle flux density in the radiation belts. Periods in slower decline of the solar array output power correspond to periods in low radiation belt indices based on the NOAA POES s/c data.
\end{abstract}

Keywords. Magnetospheric physics (Energetic particles, trapped; Instruments and techniques) - Solar physics (Flares and mass ejections)

\section{Introduction}

The MAGION microsatellites (Fig. 1) for the INTERBALL Mission (Tř́ska et al., 1995) and their subsystems (Table 1) were developed and manufactured at the Institute of Atmospheric Physics, Academy of Sciences of the Czech Republic, in cooperation with the Faculty of Mathematics and Physics, Charles University, Prague, the Space Research In-

Correspondence to: P. Trŕska

(ptr@ufa.cas.cz) stitute of the Russian Academy of Sciences, Moscow, and the Technical University Graz, Austria. The scientific payload was developed in cooperation with Austria, the Czech Republic, France, Germany, Poland, Romania, Russia and Slovakia.

MAGION is a nonhermetic spacecraft, the basic body of which is shaped in the form of a 24-hedron (Fig. 1), with the distance between opposite faces being $530 \mathrm{~mm}$. On the "upper" base there is a column carrying 4 deployable, $730-\mathrm{mm}$ long booms with scientific payload sensors. The main parts of the s/c subsystems (Table 1), including the scientific payload, are located inside the basic structure. The solar array consists of twelve deployable solar panels, $196 \times 196 \mathrm{~mm}$ in size, and another six solar panels fixed to the satellite's body. All the solar panels for the MAGION satellites were manufactured by the Russian factory "Kvant-Moscow" using the same silicon-cell technology for all of them. Therefore, the solar array efficiency decrease with time in orbit between the different MAGION s/c can be compared.

MAGION-4 was launched on 3 August 1995, together with the INTERBALL-1 and, one year later on $29 \mathrm{Au}-$ gust 1996, MAGION-5 was launched, together with the INTERBALL-2 s/c, both into highly elliptical orbits (Table 2), crossing the inner magnetosphere. MAGION-4 $(58.7 \mathrm{~kg})$ and MAGION-5 $(68.5 \mathrm{~kg})$ had apogees close to $200000 \mathrm{~km}$ and $20000 \mathrm{~km}$, respectively, and both of them had initial perigees of about $800 \mathrm{~km}$. The mechanical structure and the solar array configuration used for the two s/c were identical. The solar array consisted of 18 solar panels, most of which were deployed perpendicularly to the spin axis of the s/c pointing to the Sun.

\section{Data}

The electric currents and temperatures of all the solar panels on board the MAGION satellites were regularly measured and recorded as part of the spacecraft housekeeping data. The volt-ampere characteristics of the solar panels were 
Table 1. MAGION S/C subsystems.

\begin{tabular}{ll}
\hline Power: & solar array 32 W at beginning of mission, two NiCd batteries 12 V, 4 Ah \\
Telemetry (band/power): & $137 \mathrm{MHz} / 1.5 \mathrm{~W} ; 400 \mathrm{MHz} / 2.5-5.0 \mathrm{~W} ; 1530 \mathrm{MHz} / 2 \mathrm{~W}$ \\
Digital Telemetry: & bit rate max. 40 kbit/s \\
Analog Telemetry: & broadband $0.1-60 \mathrm{kHz}$, subcarriers $0-1.3 \mathrm{kHz}$ \\
Telecommand Link: & $150 \mathrm{MHz}$ and $450 \mathrm{MHz}$ bands, 1028 direct commands, command words \\
Housekeeping: & voltages, currents, temperatures, operation status (272 items measured) \\
Attitude Sensors: & 3-axis magnetometer, 3 solar sensors and 2 infrared horizon sensors \\
Stabilization: & spin 3०/s; spin period and spin axis direction controlled by a cold gas jet system; \\
& spin axis directed towards the Sun \\
Scientific payload: & 14 instruments to study the magnetic and electric fields and waves, \\
& cold and hot plasma parameters, video imager experiment \\
Total mass: & MAGION-4 58.7 kg, MAGION-5 68.5 kg \\
\hline
\end{tabular}
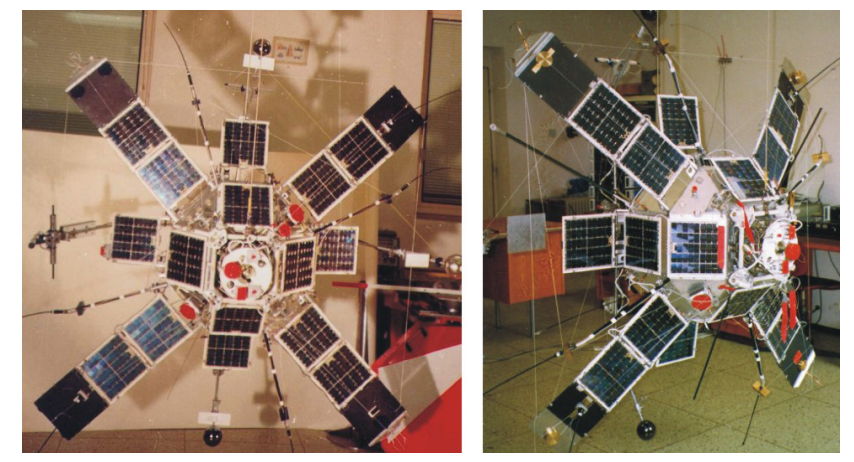

Fig. 1. The MAGION-5 flight model assembled and tested in the laboratories of the Institute of Atmospheric Physics, Prague, during winter-spring 1996 and launched on 29 August 1996 as part of the INTERBALL mission. The solar array is shown in the fully deployed position. The MAGION-4 configuration was almost identical.

Table 2. Initial orbital parameters.

\begin{tabular}{lll}
\hline & MAGION-4 & MAGION-5 \\
\hline Perigee & $800 \mathrm{~km}$ & $791 \mathrm{~km}$ \\
Apogee & $192000 \mathrm{~km}$ & $19196 \mathrm{~km}$ \\
Inclination & $62.8^{\circ}$ & $62.8^{\circ}$ \\
Orbital period & $92 \mathrm{~h}$ & $5.8 \mathrm{~h}$ \\
Launch date & 3 August 1995 & 29 August 1996
\end{tabular}

measured periodically. These data were used to evaluate the solar array degradation during the mission. The results are shown in Figs. 2 and 3.

The planned lifetime for the MAGION-4 and -5 satellites was 18 months, to fulfill the proposed scientific program of the INTERBALL Mission. In fact, MAGION-4 remained active for 26 months, and MAGION-5, although out of operation for 20 months beginning on the second day after launch date, was successfully reactivated and remained operable for more than 4 years, from May 1998 till August 2002. This

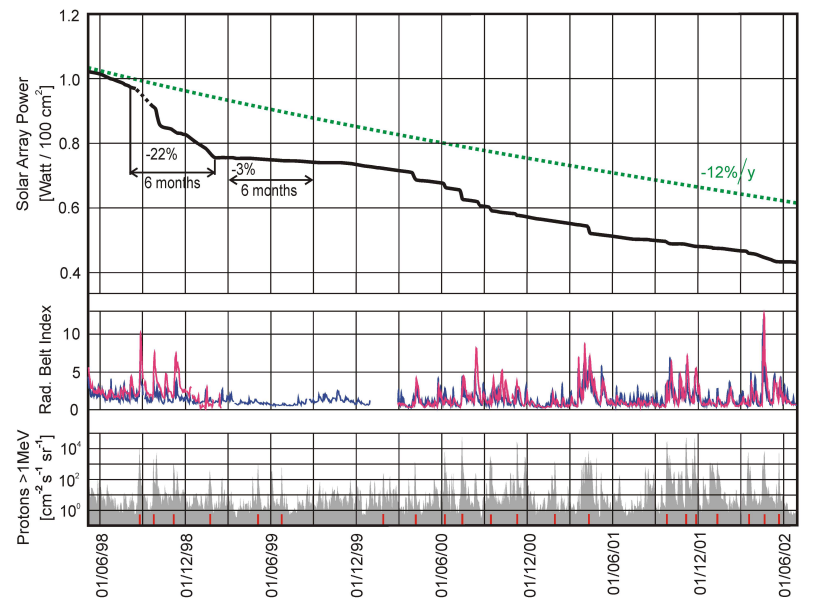

Fig. 2. MAGION-5 solar array degradation during the period from May 1998 to July 2002. The two curves in the central part of the figure show the radiation belt indices based on NOAA POES data: $>30 \mathrm{keV}$ (red) and the $>300 \mathrm{keV}$ (blue) electrons. Daily proton flux values measured by FOES-8 are shown in the lower panel. Solar proton events are denoted by red marks on the time scale. Note: most of the step-like decreases in the solar cells' output power are connected with strong solar proton events; periods with a steeper decrease in the output power correspond to periods of enhanced radiation belt indices.

enabled us to study the process of the s/c solar array degradation over a period of more than 6 years.

\section{Results}

The main results follow from Figs. 2 and 3. The long-term trend of the MAGION-5 solar array degradation is shown in Fig. 2. For comparison data on energetic particle fluxes published by the NOAA Space Environment Centre (http://www. sec.noaa.gov) are plotted in the two lower panels. The radiation belt variability can be characterised by the Radiation Belt Indices (RBI) based on NOAA's Polar-orbiting Environmental Satellites POES. The total daily RBI for $>30 \mathrm{keV}$ and 
$>300 \mathrm{keV}$ electrons is plotted in the central part of Fig. 2. The long period of a steep decrease in solar cell efficiency, occurring from May 1998 to January 1999, occurs during the long-term enhancement of RBI. A $22 \%$ loss of power was observed within a period of only 6 months. On the contrary, the period of February-August 1999, where the decrease in solar cell efficiency was slow, is a period of very low radiation belt indices. It can be concluded that radiation belt variability (see, for instance, Friedel et al., 2002 and Reeves et al., 2003) and the long-term effect of the Earth's radiation belts play an important role in the MAGION-5 solar cells degradation. The lower panel shows the $>1 \mathrm{MeV}$ proton flux measured at geostationary orbit by FOES-8. The sudden (steplike) decreases of the solar array output power observed on MAGION-5 are related to energetic proton flux peaks, most of which are connected with solar proton events. The first case of a step-like solar array degradation was observed on MAGION-5 in real time during the solar proton flare of 30 September 1998.

Figure 3 shows the difference between the MAGION-4 and MAGION-5 solar cell degradation. This can be explained mainly by the essential difference between the two orbits crossing the radiation belt region for different lengths of time. MAGION-4 spent about $4 \%$ of the time in the radiation belts, but MAGION-5 more than $40 \%$.

\section{Conclusions}

The major conclusions of this study are listed below:

1. Solar proton events can have an immediate negative effect on the s/c solar array efficiency;

2. Strong solar proton events can cause a step-like decrease in the solar array power output;

3. Cases of a distinct but not step-like decrease in the solar array power output were observed and can be explained by an increase in the Radiation Belt particle flux density connected with enhanced solar and/or geomagnetic activity;

4. Periods of a slow decrease in the solar array output power correspond to periods of low radiation belt indices;

5. The long-term effect of the radiation belt particles is the main cause of the steeper degradation of the MAGION5 solar array;

6. This study has shown that the solar array efficiency can be used as a supplementary indicator of space weather radiation effects on $\mathrm{s} / \mathrm{c}$.

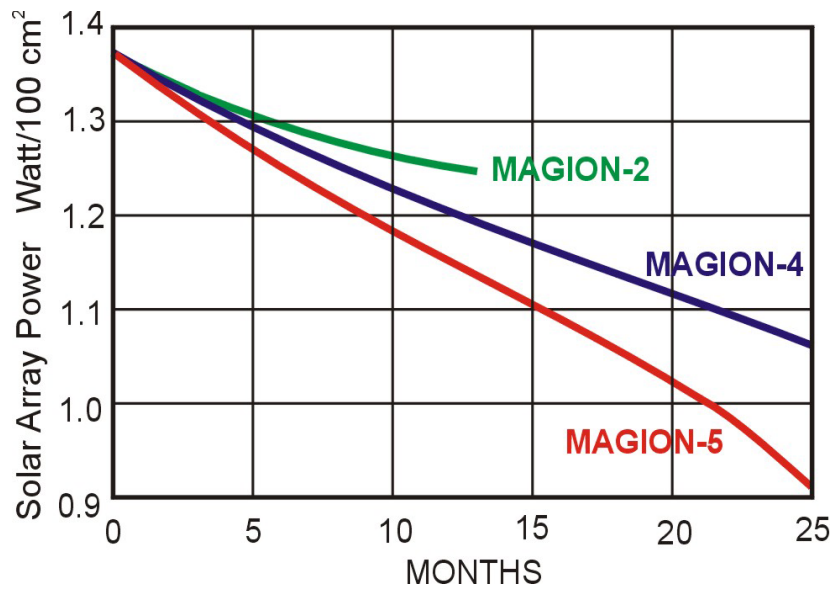

Fig. 3. MAGION-4 and MAGION-5 solar array degradation during the 25 months after launch. Most of the differences between these two curves can be explained by the effect of the radiation belts, which is more than 10 times stronger along the orbit of MAGION-5 than MAGION-4. The solar array degradation curve measured on the low-orbiting MAGION-2 (apogee $2400 \mathrm{~km}$ ) is shown for comparison.

Acknowledgements. We wish to thank the NOAA Space Environment Center for making available satellite data on Space Weather parameters. This study was partly supported by the grants No OK162 and No ME651 of the Ministry of Education of the Czech Republic.

Topical Editor T. Pulkkinen thanks K. Kudela and M. J. Rycroft for their help in evaluating this paper.

\section{References}

Friedel, R. H. W., Reeves, G. D., and Obara, T.: Relativistic electron dynamics in the inner magnetosphere - a review, J. Atmos. SolarTerr. Phys., 64, 265-282, 2002.

Reeves, G. D., McAdams, K. L., Friedel, R. H. W., and O`Brien, T. P.: Acceleration and loss of relativistic electrons during geomagnetic storms, Geophys. Res. Lett., 30 (10), 1529 , doi:10.1029/2002GL016513, 2003.

Tříska, P., Vojta, J., and Agafonov, Y.: The INTERBALL Subsatellites, in INTERBALL Mission and Payload, CNES-IKI, 100113, 1995. 